\title{
Assessment of long-lasting insecticidal net coverage, use and physical integrity one year after universal distribution campaign in Plateau department in South- East Benin
}

Filémon T. Tokponnon ${ }^{1,2,5,6 *}$, Yolande Sissinto ${ }^{3}$, Aurore Hounto Ogouyémi ${ }^{3}$, Arthur Sovi ${ }^{5,6}$, Virgile Gnanguenon ${ }^{5,6}$, Adicath Adéola Adéothy ${ }^{3}$, Abel Wapo ${ }^{3}$, Bruno Aholoukpe ${ }^{1,2}$, Patrick Makoutodé $^{3}$, Alioun Adéchoubou ${ }^{1}$, Ossè Razaki ${ }^{5,6}$, Raphael N'guessan ${ }^{7}$, Dina Gbénou ${ }^{4}$, Mariam Oke ${ }^{1,2}$, Dorothée Kinde Gazard ${ }^{2}$, Achille Massougbodji ${ }^{3}$ and Martin C. Akogbéto ${ }^{5}$

\author{
${ }^{1}$ National Malaria Control Program, Cotonou, Benin. \\ ${ }^{2}$ Ministry of Health, Benin. \\ ${ }^{3}$ Faculté des Sciences de la Santé de l'Université d'Abomey Calavi, Benin. \\ ${ }^{4}$ World Health Organisation, Benin. \\ ${ }^{5}$ Faculte des Sciences et Techniques de l'Université d'Abomey-Calavi, Benin. \\ ${ }^{6}$ Centre de Recherche Entomologique de Cotonou (CREC), Cotonou, Benin. \\ ${ }^{7}$ London School of Hygiene and Tropical Medicine, Kepel Street, London, UK.
}

Accepted 20 January, 2014

\begin{abstract}
Long-lasting insecticidal nets (LLINs) have proved to be an important tool for the malaria control and other vector-borne diseases. Benin, by its National Malaria Control Program, conducted in July, 2011 a universal distribution campaign where approximately 5 million of nets were distributed. But after this mass-distribution, questions arise: Do people effectively use or not use the mosquito nets freely distributed? To clarify these questions, this study was conducted on LLINs coverage, use and physical condition in Benin one year after their distribution. The households were randomly selected from 32 clusters. Data on bed net ownership and usage, physical condition of the nets, other characters and issues related to sourcing were asked of all targets to assess the origins of LLIN found at the household level. Of the total surveyed, $88.96 \%$ had at least one LLIN. $87.19 \%$ of these nets come from the last campaign, $\mathbf{9 . 1 \%}$ were from pregnant women voucher clinic delivery systems and $3.20 \%$ were purchased full price. $84 \%$ of the nets were reportedly used the night preceding the survey. Around $89 \%$ of the total of LLINs observed was in good condition. The universal distribution campaign in Benin has significantly increased LLIN coverage and ownership policy in the community.
\end{abstract}

Key words: Long-lasting insecticidal nets (LLINs), coverage, use, physical integrity, Benin.

INTRODUCTION

Long-lasting insecticidal nets (LLINs) have proved to be an important tool for the control of malaria and other

*Corresponding author. E-mail: filemont@yahoo.fr. Tel: (229) 97272631. Fax: (229) 21333930. 
vector-borne diseases (World Health Organisation (WHO), 2005). Several studies in malaria endemic countries have shown the usefulness of LLINs in reducing man-vector contact from malaria (Greenwood et al., 2005; Lengeler, 2004; Eisele et al., 2006; Thwing et al., 2008). It is a technology based on the slow release of pyrethroid insecticides, rendering it wash-resistant and extending insecticide residual effectiveness to at least three years without the need of re-treatment. This is why the recent objective of roll back malaria (RBM) focuses duplication of efforts including maintaining universal coverage of nets to achieve a $75 \%$ reduction compared to 2000 , the number of reported malaria cases in endemic countries in the African region, 2015 (OMS, 2011; AFR/RC50/12 - WHO, 2012) .

Benin, by its National Malaria Control Program, supported since 2000 the initiative RBM and conducted in July, 2011 a universal distribution campaign where approximately 5 million of nets were distributed. This distribution is intended to significantly increase the national coverage of insecticide-treated nets. Before the distribution, the proportion of households owning at least one net at national level was estimated at $52 \%$ (PNLPAFRICARE BENIN-CRS BENIN, 2010). After the distribution of July, 2011, this proportion was around 86.4\% (PNLP, 2011). In the net level analysis, factors independently associated in both surveys with reduced likelihood that a net would be used were: increasing net age, increasing damage of nets, increasing household net density (nets/person). Some studies have shown that several factors are associated with LLIN ownership and effective use (Graves et al., 2011). Factors associated with ownership were assumed to be: cultural beliefs and practices mechanisms of LLIN distribution and distance to LLIN suppliers, rumours about LLINs and social support and pressure (Wiseman et al., 2007; Baume and Marin, 2007). But factors associated with net used were reported to be: perceived benefits and disadvantages of nets, trust in health workers providing health education and LLINs, knowledge of appropriate net use/care practices, and net-hanging skills, household size and composition, the number of children under five years of age and use of other vector control measures (Toé et al., 2009; Edelu et al., 2010). Other studies conducted in Benin showed that several mosquito nets after 12 month of use had already holes (Gnanguenon, personnal communication). From these observations, questions arise: Do people effectively use the mosquito nets freely distributed? Or do people not use LLINs to their insufficient number or their poor physical condition? To clarify these questions, we conducted a study on insecticide-treated nets coverage, use and physical condition in plateau department in southern Benin one year after the distribution. This study aimed to provide useful data on the effectiveness of the distribution campaign.

\section{METHODOLOGY}

\section{Study area}

Plateau is a county of Benin in West Africa. The selection of this county was based on its geographic accessibility, the high use of mosquito nets by children under 5 . Entomological surveys conducted in the plateau have shown that there are both high and low pyrethroids resistance areas (Yadouleton et al., 2010). According to the general report of the distribution campaign, $85.5 \%$ of the households received a LLIN with an average of 2.7 LLINs/Household. Ketou, Pobe, Adja-Ouere, Ifangni and Sakete are the top 5 cities that compose it. But our study was focused on only four districts (Ketou, Pobe, Ifangni and Sakete). Ifangni district is located at $2^{\circ} 43^{\prime} 14^{\prime \prime} \mathrm{E}$ and $6^{\circ} 38^{\prime} 56 " \mathrm{~N}$; its area is $242 \mathrm{~km}^{2}$ representing $7.28 \%$ of Plateau territory. Sakete district is located at $2^{\circ} 39^{\prime} 7^{\prime \prime} \mathrm{E}$ and $6^{\circ} 46^{\prime} 3^{\prime \prime} \mathrm{N}$; covering an area of $432 \mathrm{~km}^{2}$, it represents $13.29 \%$ of plateau territory. Ketou is located is at $2^{\circ} 36^{\prime}$ $4^{\prime \prime} \mathrm{E}$ and $7^{\circ} 27^{\prime} 21^{\prime \prime} \mathrm{N}$; it has an area of $1775 \mathrm{~km}^{2}$, representing $54.38 \%$ of Plateau county's area. Pobè district is located at $2^{\circ} 41^{\prime}$ 51 "E and $7^{\circ} 5^{\prime} 12 " \mathrm{~N}$; it has an area of $400 \mathrm{~km}^{2}$, representing $11 \%$ of the county's area. 32 rural villages were selected through all four districts (Figure 1).

\section{Study design}

Larvae prospection's for insecticides susceptibility tests on Anopheles gambiae, main malaria vector in Benin have been conducted in many villages of the targeted districts. This baseline study on the resistance of malaria vectors to deltamethrin in the department of Plateau helped to make the choice of sentinel villages where various activities were held in our work. A total of 32 clusters were selected including 17 clusters at Ifangni, 6 at Sakété, 2 at Pobè and 8 at Kétou. Each cluster (village) was composed of several hamlets and comprised a minimum of 100 Children under five years old. Household cross-sectional surveys were undertaken in each cluster in May and August, 2012, conducting during high malaria transmission period. The survey covered the targeted groups in different villages. The choice of the targeted population has followed the standards set in the collection of basic data on morbidity and mortality due to malaria in the monitoring/evaluation RBM/RBM in Benin in 2004 (Kinde-Gazard et al., 2004). The targeted persons by cluster were: 30 mothers of children or care for children less than 5 years to evaluate fever or malaria during the last two weeks, 25 Pregnant women in the third trimester of pregnancy and women who gave birth in the last 6 months to assess malaria prevention, 30 householders for the availability and use of LLINs.

The households were randomly selected from each cluster. Data on bed net ownership and usage, physical condition of the nets, demographics of household members, other characters and issues related to sourcing were asked of all targets to assess the origins of LLIN found at the household level. Data were gathered using an adapted version of the standard Malaria Indicator Survey (RBM, 2013). Specific questions relating to the Universal Campaign Coverage process were asked to the householder and to the mothers of children or care for children less than 5 years. The physical condition of the nets was estimated using one of the two indicators recommended by WHO: the proportion of LLINs with any hole(s) (WHO, 2011). The main hole category in the LLINs was recorded as follows: 


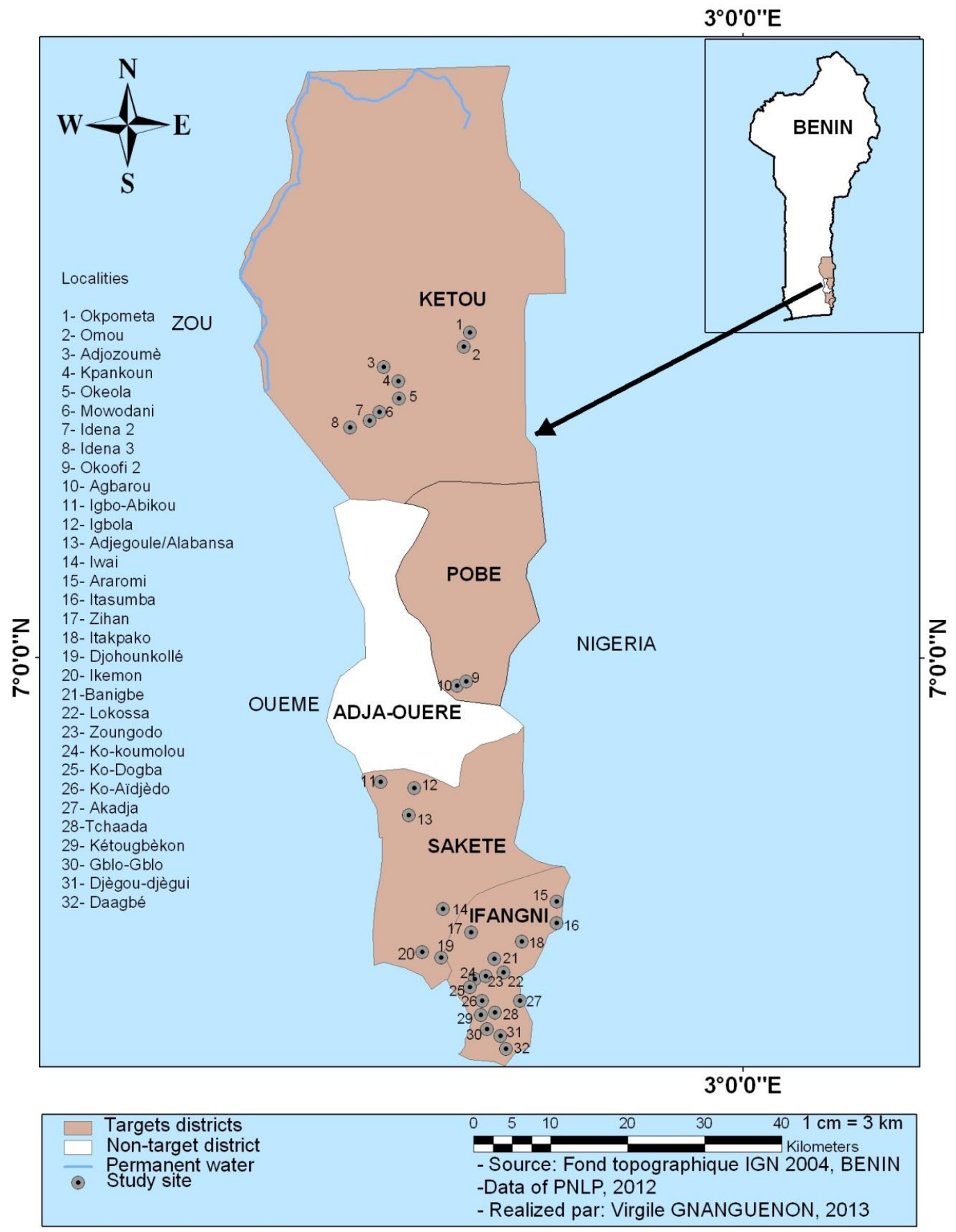

Figure 1. Map showing the study villages in Plateau department (Benin).

T1: holes size $<$ thumb $(0.5$ to $2 \mathrm{~cm})$;

T2: holes size $>$ thumb $<$ fist $(2$ to $10 \mathrm{~cm})$;

T3: holes size $>$ fist $<$ head $(10$ to $25 \mathrm{~cm})$;

T4: holes size $>$ head $(>25 \mathrm{~cm})$.

\section{Statistical analysis}

Interviews were conducted using questions. At the end of the survey, data were recorded with Epi-Info and data were transferred 
Tokponnon et al.

Table 1. Background characteristics of the households surveyed.

\begin{tabular}{lc}
\hline Characteristic & Frequency $(\%)$ \\
\hline Sex of the heads of households $(\mathbf{n}=\mathbf{9 6 0})$ & \\
Male & $386(40.20)$ \\
Female & $574(59.80)$ \\
Educational level of the heads of households & \\
Illiterate & $655(68.23)$ \\
Elementary & $188(19.58)$ \\
Post elementary & $117(12.19)$ \\
Household size $(\mathbf{n}=\mathbf{4 6 8 8})$ & \\
Children under 5 years & $1339(28.56)$ \\
Pregnants women & $800(17.06)$ \\
Person over 5 years & $2549(54.37)$ \\
\hline
\end{tabular}

into SPSS 16.0 software. The investigators had cleaned and analysed the data using the same software program. Household ownership of LLIN was calculated as a proportion of households having at least one LLIN among the total surveyed households. LLIN use was estimated as the proportion of households using at least one LLIN in the LLIN owning households. Once the LLIN ownership and use were determined; the data were filtered into a separate file of LLIN owned households. Then, households using LLINs were compared to those who did not use any to identify the factors associated with LLINs non-use. Barriers of LLIN use were determined by using enter method multivariate logistic regression model. Data on the physical integrity of LLINs and those relating to the origins of LLINs were extracted. The various holes observed were divided into four and frequencies were estimated to assess the general condition of operation of LLINs (WHO, 2011; Kilian, 2012).

\section{Ethics approval}

This study was planned and approved by the Ministry of Health. The protocol was also reviewed and approved by National Ethics Committee for Health Research at the Ministry of Health. A briefing note indicating the objectives of the study, the advantages and disadvantages was given to the respondents in order to obtain consent. Confidentiality was respected and questionnaires were anonymous.

\section{RESULTS}

\section{Study households characteristics}

960 households and 4688 people were included in the survey and the response rate was $100 \%$ (Table 1). $59.80 \%$ of the heads of households interviewed were females versus $40.20 \%$ of males. $68.23 \%$ of the heads of households were illiterate, $19.58 \%$ have elementary school degree and $12.19 \%$ have an educational level over elementary school degree. Of the 4688 people included (Table 1), 1339 (28.56\%) were under five years old; $800(17.06 \%)$ were reported to be pregnant women and 2549 (54.37\%) were people over five years old (without pregnant women).

\section{LLINs ownership}

Of the total surveyed households, $88.96 \%$ had at least one LLIN while $11.04 \%$ did not have any type of mosquito nets. The majority of households that owned LLIN had either one or two LLINs irrespective of their household size. $28.22 \%$ (25.47 to 31.16 ) had one LLIN, $31.85 \%$ (29.00 to 34.89 ) had two LLINs, $16.76 \%$ (14.54 to 19.27) had three LLINs and $12.18 \%$ (10.27 to 14.41$)$ had four LLINs. The number of ITNs did not vary significantly between cluster (Table 2) and the average LLIN ownership among LLIN owned household was 1.82 (Table 2). $87.19 \%$ (84.76 to 89.27 ) of these nets come from the National distribution campaign of $2011,9.1 \%$ (7.79 to 11.78 ) were from pregnant women voucher clinic delivery systems and $3.20 \%(2.21$ to 4.61$)$ were purchased full price (Figure 2).

\section{Factors associated with ITN ownership}

The sex of the heads of households (male and female) as well as their education level were not associated with ITN ownership $(p>0.05)$. Also, the composition of the household size in children under five, pregnant women and persons over five years old was not associated with ITN ownership $(p>0.05)$ (Table 3$)$.

\section{ITNs utilization}

Of the total of 1746 reported LLINs, $42.96 \%(n=750)$ LLINs were observed by the surveyors. $84 \%$ of the nets were reportedly used the night preceding the survey. The 
Table 2. LLINs ownership by cluster.

\begin{tabular}{|c|c|c|c|c|c|}
\hline Parameter & Cluster & LLINs & No. of households & Mean & $\mathrm{Cl} 95 \%$ \\
\hline \multirow{8}{*}{ Ketou } & Okpometa & 52 & 30 & 1.73 & {$[1.40-2.05]$} \\
\hline & Omou & 69 & 30 & 2.3 & [2.03-2.56] \\
\hline & Adjozounme & 82 & 30 & 2.73 & [2.54-2.92] \\
\hline & Kpankoun & 59 & 30 & 1.97 & [1.69-2.25] \\
\hline & Oke Ola & 38 & 30 & 1.27 & {$[1.02-1.52]$} \\
\hline & Mowodani & 74 & 30 & 2.47 & {$[2.24-2.70]$} \\
\hline & Idena2 & 45 & 30 & 1.5 & [1.11-1.88] \\
\hline & Idena3 & 49 & 30 & 1.63 & {$[1.24-2.01]$} \\
\hline \multirow{2}{*}{ Pobe } & Okoffi 2 & 73 & 30 & 2.43 & {$[2.20-2.75]$} \\
\hline & Agbarou & 44 & 30 & 1.47 & [1.11-1.82] \\
\hline \multirow{6}{*}{ Sakete } & Igboabikou & 39 & 30 & 1.3 & [1.04-1.55] \\
\hline & Igbola & 54 & 30 & 1.8 & [1.44-2.15] \\
\hline & Adjegounle/Alabansa & 48 & 30 & 1.6 & {$[1.22-1.97]$} \\
\hline & Iwai & 61 & 30 & 2.03 & [1.68-2.37] \\
\hline & Ikemon & 52 & 30 & 1.73 & {$[1.51-1.94]$} \\
\hline & Djohounkolle & 53 & 30 & 1.77 & [1.51-2.02] \\
\hline \multirow{17}{*}{ Ifangni } & Akadja & 69 & 30 & 2.3 & [2.08-2.51] \\
\hline & Araromi & 40 & 30 & 1.33 & {$[0.92-1.73]$} \\
\hline & Banigbe & 48 & 30 & 1.6 & {$[1.28-1.91]$} \\
\hline & Daagbe & 49 & 30 & 1.63 & {$[1.23-2.02]$} \\
\hline & Djegou Djedji & 65 & 30 & 2.17 & {$[1.93-2.40]$} \\
\hline & Gblo Gblo & 23 & 30 & 0.77 & {$[0.43-1.10]$} \\
\hline & Ita Kpako & 59 & 30 & 1.97 & [1.62-2.32] \\
\hline & Itassumba & 56 & 30 & 1.87 & [1.54-2.19] \\
\hline & Ketougbekon & 47 & 30 & 1.57 & [1.24-1.90] \\
\hline & Ko Dogba & 56 & 30 & 1.87 & [1.54-2.19] \\
\hline & Ko-Aîdjedo & 70 & 30 & 2.33 & {$[2.12-2.54]$} \\
\hline & Kokoumolou & 51 & 30 & 1.7 & [1.42-1.97] \\
\hline & Lokossa & 42 & 30 & 1.4 & {$[1.00-1.79]$} \\
\hline & Tchaada & 64 & 30 & 2.13 & {$[1.85-2.40]$} \\
\hline & Zian & 70 & 30 & 2.33 & [1.98-2.67] \\
\hline & Zougoudo & 45 & 30 & 1.5 & [1.09-1.90] \\
\hline & Total & 1746 & 960 & 1.82 & {$[1.76-1.87]$} \\
\hline
\end{tabular}

$\mathrm{Cl}=$ confidence interval.

proportion of nets in use varies from 47 to $100 \%$, but not significantly different from one cluster to another (Table 4). It was only at Araromi that the level of net use was significantly low compared to other clusters. Among the target groups, $76.4 \%$ (73.46 to 79.34$)$ of pregnant women really used LLINs, $82.88 \%$ (80.87 to 84.91$)$ children under 5 years used nets while $69.78 \%$ (68.22 to 71.34 ) people over 5 years were reported as using LLINs (Figure 3). On the 807 LLINs observed, around $16 \%$ was found with hole(s) (Table 5). No significant difference was observed between categories of holes (T1 to T4) and while comparing the physical condition of the nets by the level of instruction of their owners $(p<0.05)$.

\section{DISCUSSION}

ITNs coverage was increased by the universal distribution 


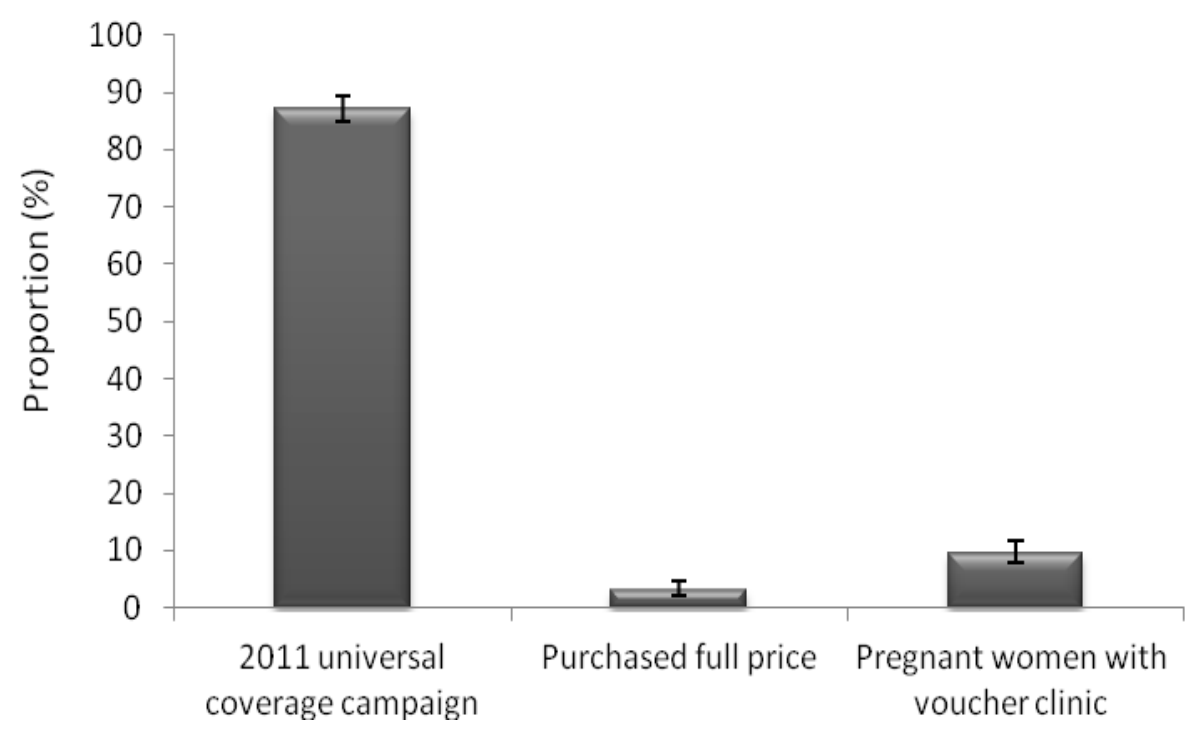

Figure 2. Source of ITN ownership.

Table 3. Multivariate regression on ITN ownership.

\begin{tabular}{lccc}
\hline Factors & \% ITN ownership (n) & $\mathbf{C l}=95 \%$ & p-value \\
\hline Heads of households & $88.96(854)$ & & \\
& & & \\
Sex of the heads of households & $43.85(421)$ & {$[40.72-46.99]$} & 0.680 \\
Male & $45.10(433)$ & {$[41.96-48.25]$} & \\
Female & & & \\
& & & \\
Educational level of the heads of households & $60.31(579)$ & {$[57.22-63.41]$} & \\
Illiterate & $17.5(168)$ & {$[15.10-19.90]$} & 0.332 \\
Elementary & $11.15(107)$ & {$[9.16-13.14]$} & \\
Post elementary & & & \\
\hline
\end{tabular}

$\mathrm{n}=$ number $\mathrm{Cl}=$ Confidence Interval.

distribution campaign with a proportion of $88.96 \%$ of households that owned at least one ITN. This proportion is higher when compared to the preceding distribution campaign evaluation (Tokponnon et al., 2013), and the average number of ITNs per household was around 2 . Mosquito nets (LLINs) that were from the distribution campaign were significantly higher (87\%) comparatively to those that were purchased full price $(3 \%)$ or received from pregnant women antenatal consultation (9\%). In our study, the average number of LLINs per household visited was 1.82 considering the 960 households. The average household size was 4.88 people visited. Thus we can say that about two nets are available for 5 people at the household level. However, the objective of this campaign is to increase the distribution level of $56 \%$ coverage (PNLP, 2012) at least $80 \%$ and have a LLIN for two people in the general population.

In the protocol of the LLIN distribution campaign of July, 2011, households of two people were covered with two LLINs and this rule has been well respected in rural areas in which the distribution has been fewer problems (Tokponnon et al., 2013). Our observations were consistent with the same requirements a year after the campaign. A disadvantage of the distribution was that $11 \%$ of households did not receive LLINs (PNLP, 2012). There were no significant differences between the availability of LLINs in different villages when considering the proportion of households with at least two LLINs. This 


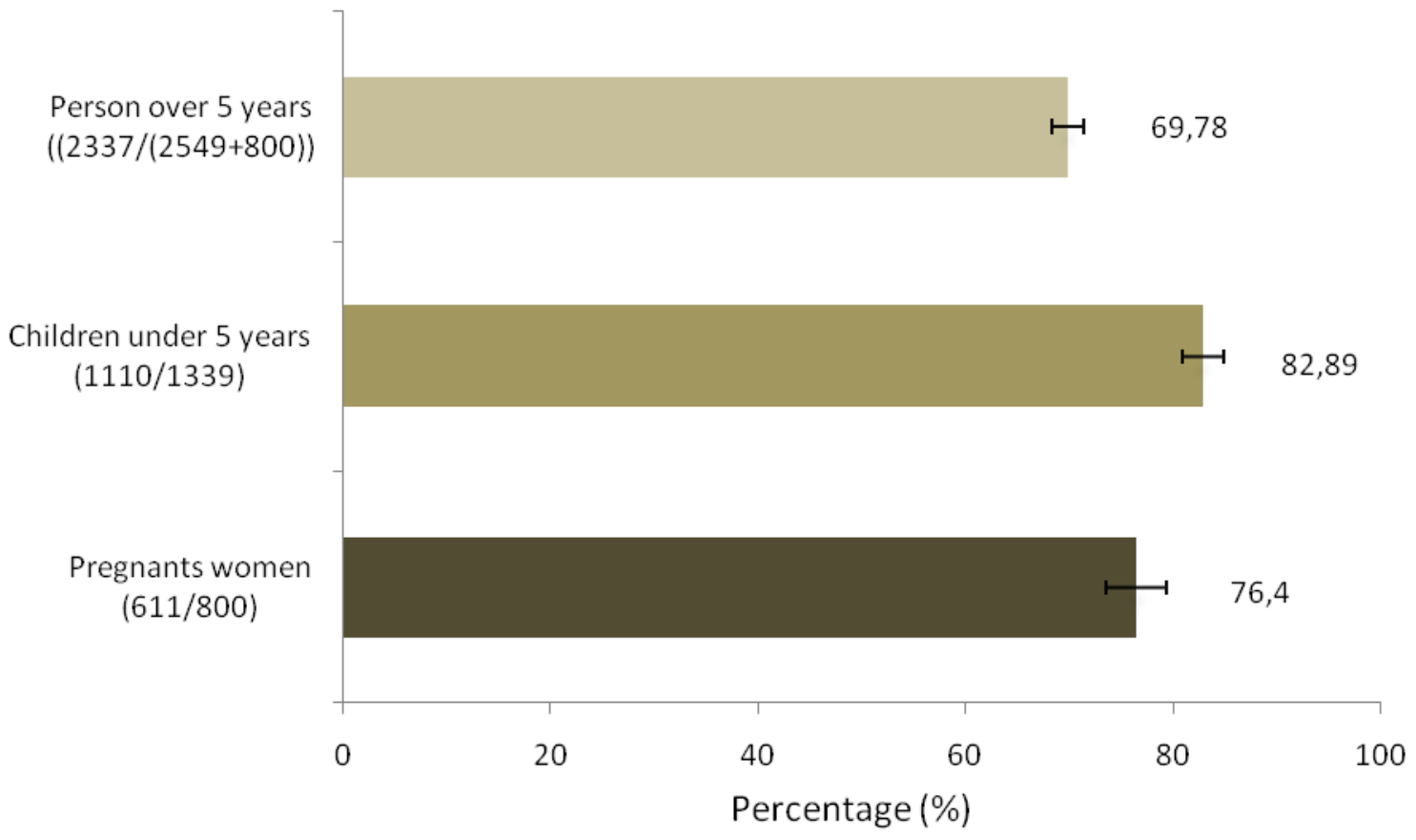

Figure 3. Net usages in target and non target group.

Table 4. Multivariate regression on ITN use.

\begin{tabular}{|c|c|c|c|c|c|c|c|}
\hline \multirow{2}{*}{ Districts } & \multirow{2}{*}{ Clusters } & \multicolumn{3}{|c|}{ LLIN utilization } & \multirow{2}{*}{ Proportion M+ (\%) } & \multirow{2}{*}{ OR } & \multirow[b]{2}{*}{$p$} \\
\hline & & M- & M+ & Total & & & \\
\hline \multirow{8}{*}{ Ketou } & Okpometa & 7 & 23 & 30 & 77 & 3.75 & 0.0194 \\
\hline & Omou & 1 & 29 & 30 & 97 & 33.14 & 0.0012 \\
\hline & Adjozounme & 0 & 30 & 30 & 100 & 69.41 & 0.0039 \\
\hline & Kpankoun & 3 & 27 & 30 & 90 & 10.26 & 0.001 \\
\hline & Oke Ola & 7 & 23 & 30 & 77 & 3.75 & 0.0194 \\
\hline & Mowodani & 9 & 21 & 30 & 70 & 2.66 & 0.0698 \\
\hline & Idena 2 & 10 & 20 & 30 & 67 & 2.28 & 0.1208 \\
\hline & Idena 3 & 8 & 22 & 30 & 73 & 3.14 & 0.0379 \\
\hline \multirow{2}{*}{ Pobe } & Okoffi 2 & 4 & 26 & 30 & 87 & 7.42 & 0.002 \\
\hline & Agbarou & 13 & 17 & 30 & 57 & 1.49 & 0.4391 \\
\hline \multirow{6}{*}{ Sakete } & Igboabikou & 3 & 27 & 30 & 90 & 10.26 & 0.001 \\
\hline & Igbola & 4 & 26 & 30 & 87 & 7.42 & 0.002 \\
\hline & Adjegounle/Alabansa & 11 & 19 & 30 & 63 & 1.97 & 0.1967 \\
\hline & Iwai & 4 & 26 & 30 & 87 & 7.42 & 0.002 \\
\hline & Ikemon & 1 & 29 & 30 & 97 & 33.14 & 0.0012 \\
\hline & Djohounkolle & 5 & 25 & 30 & 83 & 5.71 & 0.0044 \\
\hline \multirow{4}{*}{ Ifangni } & Akadja & 6 & 24 & 30 & 80 & 4.5714 & 0.0094 \\
\hline & Araromi & 16 & 14 & 30 & 47 & 1 & - \\
\hline & Banigbe & 6 & 24 & 30 & 80 & 4.5714 & 0.0094 \\
\hline & Daagbe & 9 & 21 & 30 & 70 & 2.66 & 0.0698 \\
\hline
\end{tabular}


Table 4. Contd.

\begin{tabular}{lcccccc}
\hline Djegou - Djegi & 6 & 24 & 30 & 80 & 4.5714 & 0.0094 \\
Gblo-Gblo & 14 & 16 & 30 & 53 & 1.3 & 0.6058 \\
Ita - Kpako & 0 & 30 & 30 & 100 & 69.41 & 0.0039 \\
Itassumba & 2 & 28 & 30 & 93 & 16 & 0.0007 \\
Ketougbekon & 11 & 19 & 30 & 63 & 1.97 & 0.1967 \\
Ko Dogba & 9 & 21 & 30 & 70 & 2.66 & 0.0698 \\
Ko Aïdjedo & 0 & 30 & 30 & 100 & 69.41 & 0.0039 \\
Kokoumolou & 9 & 21 & 30 & 70 & 2.66 & 0.0698 \\
Lokossa & 10 & 20 & 30 & 67 & 2.28 & 0.1208 \\
Tchaada & 9 & 21 & 30 & 70 & 2.66 & 0.0698 \\
Zian & 2 & 28 & 30 & 93 & 16 & 0.0007 \\
Zougoudo & 9 & 21 & 30 & 70 & 2.66 & 0.0698 \\
Total & 208 & 752 & 960 & 78.3 & & \\
\hline
\end{tabular}

$\mathrm{M}+$ : household who's everybody use LLIN the days before survey. M-: household who's not everybody use LLIN the days before survey. OR: odd ratio; Significant at $p<0.05$ level.

Table 5. Physical condition of LLINs.

\begin{tabular}{|c|c|c|c|c|c|c|c|}
\hline \multirow{2}{*}{ Level of instruction } & \multirow{2}{*}{ LLINs without hole } & \multicolumn{4}{|c|}{ LLINs with holes } & \multirow{2}{*}{$\begin{array}{l}\text { Total LLINs } \\
\text { with hole(s) }\end{array}$} & \multirow{2}{*}{$\begin{array}{l}\text { \% LLINs with } \\
\text { holes }\end{array}$} \\
\hline & & T1 & T2 & T3 & T4 & & \\
\hline Illiteracy & 542 & 28 & 52 & 15 & 11 & 106 & 16,36 \\
\hline Primary school & 163 & 10 & 12 & 3 & 3 & 28 & 14,66 \\
\hline Post primary school & 102 & 7 & 3 & 4 & 1 & 15 & 12,82 \\
\hline Total & 807 & 45 & 67 & 22 & 15 & 149 & 15,58 \\
\hline
\end{tabular}

proportion was higher compared to those with three or four due to the fact that LLIN distribution campaign has limited the number of nets distributed for two people and a maximum of 8 LLINs for large households at the same size.

This observation is a good performance and the coverage attained was similar to what has been achieved in other countries (Tanzania, Nigeria and Togo) (West et al., 2012; Stevens et al., 2013). Continuous distribution of LLINs to pregnant women and children under five is an important way to increase nets coverage and replace torn nets (RBM, 2011). An additional continuous distribution system, via NGOs for example, can also be planned for other households. $78 \%$ of the net observed were reported to be used the previous night, and the proportion of nets use did not vary significantly between clusters, suggesting that awareness for net use was a success. But full net used by target group was not achieved.

$76.4 \%$ of pregnants women were using ITNs while only $82.88 \%$ of children under five were using ITNs. This observation suggests that net usage could be improved in target group.
The high ITNs usage could be a consequence of the increased availability of ITNs at the household level due to the universal distribution campaign. This observation has already been noticed in Tanzania by West and colleagues (West et al., 2012). The level of ITN use could also be influenced by high temperature and mosquito density (Graves et al., 2011). But comparatively to other studies, ITN usage observed in target group in this study was higher than those observed in Tanzania and Nigeria (Ye et al., 2012; West et al., 2012). ITN ownership and use seems to reflect the general coverage and ITNs ownership in the whole population. The proportion of LLINs from the distribution campaign found in good condition was significantly higher than those observed in serviceable condition or torn out.

\section{Conclusion}

The universal distribution campaign in Benin has significantly increased ITN coverage and ownership policy in the community. Non target persons and target 
persons (pregnant women and children under five) had similar level in ITN ownership and usage. The level of ITN ownership and usage were also similar between villages. This is an important indicator of universal coverage goal. But additional effort must be done to fully achieve universal coverage goal, and routine distribution must be used to maintain ITN coverage.

\section{ACKNOWLEDGEMENTS}

We are grateful to the WHO and Bill \& Melinda Gates Foundation which supported financially this study. The authors would also like to thank the populations of 32 clusters, the team of health system in the Plateau department, and the investigators for their collaboration.

\section{REFERENCES}

AFR/RC50/12 - WHO (2012). Regional Office for Africa [http://www.afro.who.int/fr/downloads/doc_details/1106afrrc5012.html?tmpl=component].

Baume CA, Marin MC (2007). Intra-household mosquito net use in Ethiopia, Ghana, Mali, Nigeria, Senegal, and Zambia: are nets being used? Who in the household uses them? Am. J. Trop. Med. Hyg. 77:963-971.

Edelu B, Ikefuna A, Emodi J, Adimora G (2010). Awareness and use of insecticide-treated bed nets among children attending outpatient clinic at UNTH, Enugu - the need for an effective mobilization process. Afr. Health Sci. 10:117-119.

Eisele TP, Macintyre K, Yukich J, Ghebremeskel T (2006). Interpreting household survey data intended to measure insecticide-treated bednet coverage: results from two surveys in Eritrea. Malar. J. 5:36.

Graves PM, Ngondi JM, Hwang J, Getachew A, Gebre T, Mosher AW, Patterson AE, Shargie EB, Tadesse Z, Wolkon A, Reithinger R, Emerson PM, Richards FO (2011). Factors associated with mosquito net use by individuals in households owning nets in Ethiopia. Malar. J. 10:354.

Greenwood BM, Bojang K, Whitty CJM, Targett GAT (2005). Malaria. Lancet 365:1487-1498.

Kilian A (2012). Textile Testing Methods for Nets.

Kinde-Gazard D, Gbenou D, Tohon S, Da Silva C, Nahum A, Quenum A, Houndigande E, Houndekon R, Ekoue S, Massougbodji A (2004). Indicateurs de suivi et d'évaluation en 2001 de l'initiative Faire reculer le paludisme au Bénin. Bull. Soc. Pathol. Exot. 97:349-352.

Lengeler C (2004). Insecticide-treated bed nets and curtains for preventing malaria. Cochrane Database Syst. Rev. CD000363.

OMS (2011). Rapport 2011 sur le paludisme dans le monde [http://www.who.int/malaria/world_malaria_report_2011/fr/]

PNLP-AFRICARE BENIN-CRS BENINRS (2010). Evaluation Finale Du Projet D'appui à La Lutte Contre Le Paludisme. Cotonou, 42p.

PNLP (2011). Evaluation post campagne de la distribution gratuite de MIILD en 2011 au Bénin. Cotonou, 58p.
PNLP (2012). Campagne de Distribution Gratuite Des Moustiquaires Imprégnées à Longue Durée D’action Aux Ménages Du Bénin. Cotonou: Ministère de la Santé.11p.

RBM (2011). Continuous LLIN Distributions: A Guide to Concepts and Planning/ K4Health [http://www.k4health.org/toolkits/continuousdistribution-malaria/continuous-Ilin-distributions-guide-concepts-andplanning].

RBM (2013). Malaria Indicator Surveys - Access to Reports, MIS Datasets,
[http://www.malariasurveys.org/surveys.cfm].

Stevens ER, Aldridge A, Degbey Y, Pignandi A, Dorkenoo MA, Hugelen-Padin $J$ (2013). Evaluation of the 2011 long-lasting, insecticide-treated net distribution for universal coverage in Togo. Malar. J. 12:162.

Thwing J, Hochberg N, Vanden Eng J, Issifi S, Eliades MJ, Minkoulou E, Wolkon A, Gado H, Ibrahim O, Newman RD, Lama M (2008). Insecticide-treated net ownership and usage in Niger after a nationwide integrated campaign. Trop. Med. Int. Health 13:827-834.

Toé LP, Skovmand O, Dabiré KR, Diabaté A, Diallo Y, Guiguemdé TR, Doannio JM, Akogbeto M, Baldet T, Gruénais M-E (2009). Decreased motivation in the use of insecticide-treated nets in a malaria endemic area in Burkina Faso. Malar. J. 8:175.

Tokponnon F, Aholoukpe B, Denon E, Gnanguenon V, Bokossa A, N'guessan R, Oke M, Kinde-Gazard D, Akogbeto M (2013). Evaluation of the coverage and effective use rate of Long-Lasting Insecticidal Nets after Nation-wide scale up of their distribution in Benin. Parasit. Vectors., 6:265.

West PA, Protopopoff N, Rowland MW, Kirby MJ, Oxborough RM, Mosha FW, Malima R, Kleinschmidt I (2012). Evaluation of a national universal coverage campaign of long-lasting insecticidal nets in a rural district in North-west Tanzania. Malar. J. 11:273.

WHO (2005). World Malaria Report 2005. [http://www.who.int/malaria/publications/atoz/9241593199/en/]

WHO (2011). Guidelines for monitoring the durability of long-lasting insecticidal mosquito nets under operational conditions. [http://apps.who.int/iris/handle/10665/44610]

Wiseman V, Scott A, McElroy B, Conteh L, Stevens W (2007). Determinants of bed net use in the Gambia: implications for malaria control. Am. J. Trop. Med. Hyg. 76:830-836.

Yadouleton AW, Padonou G, Asidi A, Moiroux N, Bio-Banganna S, Corbel V, N'guessan R, Gbenou D, Yacoubou I, Gazard K, Akogbeto MC (2010). Insecticide resistance status in Anopheles gambiae in Southern Benin. Malar. J. 9:83.

Ye Y, Patton E, Kilian A, Dovey S, Eckert E (2012). Can universal insecticide-treated net campaigns achieve equity in coverage and use? the case of northern Nigeria. Malar. J. 11:32. 